\title{
The burden of extrapulmonary and meningitis tuberculosis: an investigation of national surveillance data, Germany, 2002 to 2009
}

T Ducomble (DucombleT@rki.de) ${ }^{1,2}$, K Tolksdorf ${ }^{1}$, I Karagiannis ${ }^{1}$, B Hauer ${ }^{1}$, B Brodhun ${ }^{1}$, W Haas ${ }^{1}$, L Fiebig ${ }^{1}$

1. Robert Koch Institute, Department for Infectious Disease Epidemiology, Respiratory Infections Unit, Berlin, Germany

2. European Programme for Intervention Training (EPIET), European Centre for Disease Prevention and Control (ECDC) Stockholm, Sweden

Citation style for this article:

Ducomble T, Tolksdorf K, Karagiannis I, Hauer B, Brodhun B, Haas W, Fiebig L. The burden of extrapulmonary and meningitis tuberculosis: an investigation of national surveillance data, Germany, 2002 to 2009. Euro Surveill. 2013;18(12):pii=20436. Available online: http://www.eurosurveillance.org/ViewArticle. aspx?Articleld $=20436$

Article submitted on 16 November 2012 / published on 21 March 2013

Tuberculosis (TB) surveillance commonly focuses on pulmonary (PTB) where the main organ affected is the lung. This might lead to underestimate extrapulmonary TB (EPTB) forms, where in addition to the lung other sites are affected by TB. In Germany, TB notification data provide the main site and the secondary site of disease. To gain an overview of all the different EPTB forms, we analysed German TB notification data between 2002 and 2009 using information on both main and secondary disease site to describe all individual EPTB forms. Further, we assessed factors associated with meningitis using multivariable logistic regression. Solely analysing the main site of disease, lead to one third of EPTB manifestations being overlooked. Case characteristics varied substantially across individual extrapulmonary forms. Of 46,349 TB patients, $422(0.9 \%)$ had meningitis as main or secondary site. Of those, $105(25 \%)$ of the 415 with available information had died. Multivariable analysis showed that meningitis was more likely in children younger than five years and between five and nine years-old (odds ratio (OR): 4.90; $95 \%$ confidence interval (Cl): 3.40-7.07 and OR: 2.65; 95\% Cl: 1.40-5.00), in females (OR: 1.42; $95 \% \mathrm{Cl}: 1.17-1.73$ ), and in those born in the World Health Organization (WHO) regions of south-east Asia (OR: 2.38; 95\% Cl: 1.66-3.43) and eastern Mediterranean (OR: 1.51; 95\% Cl: 1.02-2.23). Overall, EPTB manifestations, including meningitis, which is often fatal, were underestimated by routine analysis. We thus recommend using all information on disease manifestation generated by surveillance to monitor severe forms and to transfer the gained knowledge to TB case management where awareness of EPTB is most important.

\section{Introduction}

Global tuberculosis (TB) control focuses on pulmonary tuberculosis (PTB) to prevent transmission and reduce the number of new cases. Thus, in surveillance, TB cases are classified as pulmonary TB whenever lungs are involved, irrespective of any additional involvement of other organs [1]. However, extrapulmonary TB (EPTB), a collective term for diverse manifestations affecting any other anatomic site than the lung parenchyma and the tracheobronchial tree, substantially contributes to the TB burden. In the European Union and European Economic Area (EU/EEA), $22 \%$ of TB patients notified in 2010 only had extrapulmonary manifestations [2]. EPTB is more common in immunocompromised individuals, especially people living with human immunodeficiency virus (HIV) [3-7], but also females and different ethnic groups [3,5-10]; for example, in the United Kingdom (UK) all non-white ethnic groups were associated with EPTB [8]. Socio-behavioural factors including smoking and alcohol abuse, in contrast, were associated with pulmonary manifestation $[6,7,11-13]$.

Some EPTB forms, such as meningitis cause severe disease. Reported case fatality ranges from 20 to $69 \%$ [14] in different settings worldwide with up to half of surviving patients presenting with irreversible sequelae, including paraplegia, blindness, motor and cognitive deficits [15-19]. Prognosis is largely influenced by early diagnosis and adequate treatment [4,17-19].

Meningitis TB most commonly occurs in infants and toddlers, mainly within three months after infection $[3,20]$. Its development may be influenced by genetic factors, differing across ethnic groups and certain strains of Mycobacterium tuberculosis complex [7,21]. Further, vitamin D deficiencies [22] and underlying conditions influencing immunocompetency, including HIV infection $[13,19,21,23]$ diabetes mellitus, malignancy and recent corticosteroid treatment, as well as alcohol abuse (in adults), have been described as risk factors for meningitis TB. Bacillus Calmette-Guérin (BCG) vaccines were reported to have a preventive effect in young children (30-82\%) [24]. 


\section{FIGURE 1}

Overview of the notified tuberculosis patients and investigated groups, Germany, 2002-2009 (n=46,730)

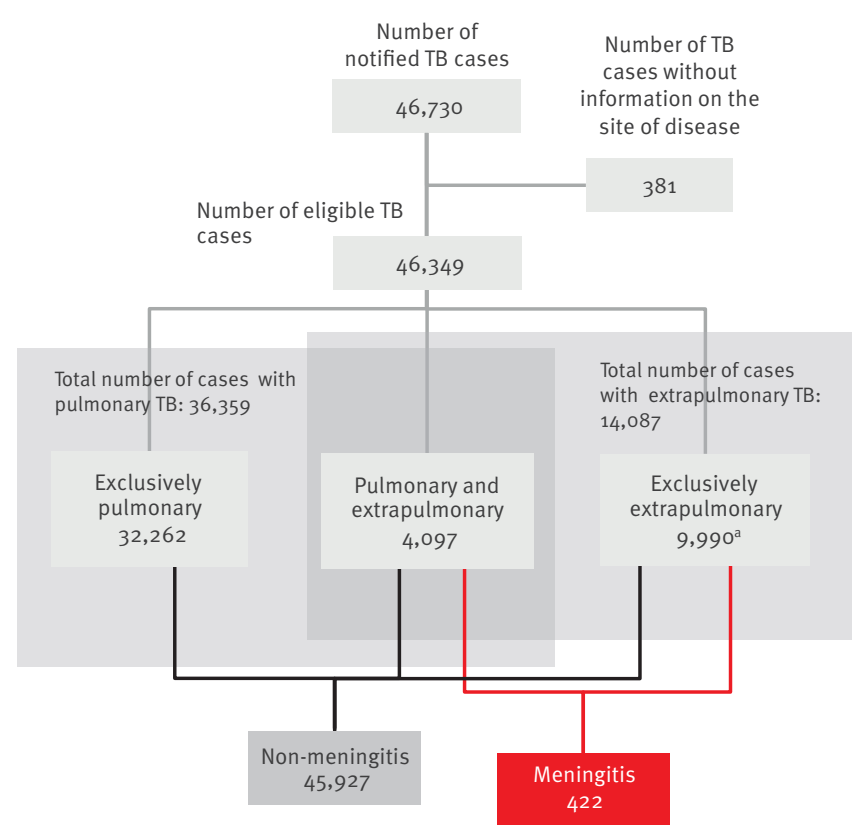

TB: tuberculosis.

28 cases with no information on the main site of disease but available information on the secondary site are included in the exclusively extrapulmonary TB cases $(n=9,990)$ presented in this flow chart.

In 2010, Germany, a low incidence country for TB (5.3 cases per 100,000 population in 2010 ), reported that $21 \%$ of patients had exclusively EPTB [25]. National TB surveillance captures disease manifestations as main and secondary site of disease (whereby only up to two sites can be recorded) and classifies extrapulmonary forms into 11 sites as recommended by the World Health Organization (WHO): intrathoracic lymph nodes (LN), extrathoracic LN, pleura, genitourinary tract, abdomen, spine, bone and joints, meninges, other central nervous system (CNS), disseminated TB and any other organ [1]. Lungs, when affected by TB, can only be recorded as the main site of disease. If two different extrapulmonary sites are affected, physicians are asked to classify the more severely affected one as main site of disease. In line with other countries, surveillance data analyses and reporting focus on the main site of disease (privileging PTB). This may lead to underestimate EPTB manifestations overall, as well as EPTB forms causing severe disease such as meningitis TB.
We conducted a study to (i) estimate the frequency of all individual EPTB forms, irrespective of the classification as main or secondary site, (ii) describe demographic and clinical characteristics of patients affected by specific extrapulmonary sites of disease and (iii) identify factors associated with meningitis TB.

\section{Methods}

\section{Data source}

We used case-based TB surveillance data from Germany between 2002 and 2009, electronically reported to the Robert Koch Institute (RKI) until 1 August 2010, and population data from the Federal Statistical Office to calculate incidences [26]. Surveillance defines active TB cases based on clinical diagnosis and the indication of a full-course of anti-TB treatment regimen with or without bacteriological confirmation or known epidemiological link to another confirmed case [27]. The notification system, case definitions and diagnostic procedures have remained largely the same over the investigation period. This is as well reflected by the stable proportion of bacteriologically-confirmed cases (72\% to $75 \%$ ) from 2002 to 2009 .

\section{Data analysis}

We grouped cases into three categories: PTB only, both PTB and EPTB, and EPTB only (Figure 1), and calculated mean annual incidences (cases/100,000 populations). Further, we compared the proportions of these three groups in 2002 to those in 2009.

We calculated the frequency of all 11 EPTB sites (i) using information regarding the main site of disease only and (ii) combining information from main and secondary sites of disease and compared the number of EPTB affected sites detected using either classifications. As up to two different disease sites per patient can be recorded, the same patient may belong to two different disease manifestation groups.

To identify characteristics of patients affected by specific extrapulmonary manifestations, we tabulated demographic (i.e. age, sex, country of birth (foreign vs. German)) and clinical information (i.e. hospitalisation, duration of hospitalisation (in days) and case fatality ratio (CFR)) by site of disease. We presented proportions for categorical variables and median and interquartile-ranges (IQRs) for continuous variables. We excluded implausible values (e.g. negative values) in the duration of hospitalisation from the analysis.

To identify factors associated with meningitis TB, we compared meningitis (both as main and as secondary site) with non-meningitis TB cases in terms of possible exposures using the chi-squared test, odds ratios (OR), $95 \%$ confidence intervals $(\mathrm{Cl})$ and two-sided p-values. Exposures examined included age, sex, country of birth, as well as being a new case, i.e. not previously treated. We grouped countries of birth into Germany, 
Effect of taking in account the main and secondary sites of tuberculosis in identifying extrapulmonary tuberculosis, Germany, 2002-2009 ( $\mathrm{n}=46,389$ patients)

\begin{tabular}{|l|c|c|c|}
\hline TB forms or TB sites & $\begin{array}{c}\text { Total TB sites according to } \\
\text { the main site of disease } \\
\text { notified } \\
(\mathrm{N}=46,321)^{\mathrm{b}}\end{array}$ & $\begin{array}{c}\text { Total TB sites resulting } \\
\text { from the main and } \\
\text { secondary sites of disease } \\
\text { notified }(\mathrm{N}=51,232)^{\mathrm{c}}\end{array}$ & $\begin{array}{c}\text { Increase of EPTB sites } \\
\text { resulting from taking } \\
\text { secondary sites into } \\
\text { account }(\%)\end{array}$ \\
\hline Pulmonary & 36,359 & 36,359 & NA \\
\hline Extrapulmonary & 9,962 & 14,873 & 50 \\
\hline Extrathoracic lymph nodes & 3,330 & 4,129 & 24 \\
\hline Pleura & 1,579 & 2,806 & 78 \\
\hline Intrathoracic lymph nodes & 1,130 & 1,812 & 60 \\
\hline Genitourinary & 1,243 & 1,590 & 28 \\
\hline Bone and joints & 610 & 835 & 37 \\
\hline Abdominal & 455 & 750 & 65 \\
\hline Spine & 373 & 544 & 46 \\
\hline Disseminated & 192 & 521 & 171 \\
\hline Meninges & $\mathbf{2 8 8}$ & $\mathbf{4 2 2}$ & \\
\hline Central nervous system & 64 & 116 & \\
\hline Other forms & 698 & 1,348 & \\
\hline
\end{tabular}

EPTB: extrapulmonary tuberculosis; NA: not applicable; TB: tuberculosis.

Up to two different TB disease sites per patient can be recorded. Lungs, when affected by TB, can only be recorded as the main site of disease. If two different EPTB sites are affected, the more severely affected is classified as main site of disease. If three or more sites are affected, the case is to classify as 'disseminated'.

a As there is one main site of disease per patient the total number of TB sites according to the main site notified, equals the number of patients.

b 28 of 46,349 patients included in the study did not have information on main site of disease. According to the rules of the notification system, these patients had only EPTB forms recorded as secondary sites.

C As up to two sites per patient can be recorded (main and secondary site) the number of total TB sites resulting from considering the main and secondary sites of disease is greater than the number of patients. The 28 patients with information on secondary sites were included in the analysis.

Turkey, Newly Independent States of the former Soviet Union (NIS), other countries of the WHO European region, as well as other WHO regions. We considered four age groups (individuals younger than 5 years, 5 to 9 years, 10 to 14 years and 15 years or older). We included variables associated at $p=0.2$ in the univariable analysis in a multivariable logistic regression analysis using forward selection. We tested pairwise interactions of independent variables at each step and only included them when the likelihood ratio test pointed to an improvement of the model with a $p$-value less than 0.05 .

We analysed data using Excel (version 11, Microsoft Corporation Redmond, Washington, USA) and Stata (version 12.1, StataCorp LP, TX, USA) software.

\section{Results}

\section{Study population}

From 2002 to 2009 , a total of 46,730 TB patients were reported in Germany (mean annual incidence of 6.3 cases per 100,000 population). Of the 46,349 patients with information on the anatomic site of disease,
32,262 (70\%) had exclusively PTB, 4,097 (8.8\%) had both PTB and EPTB and 9,990 (22\%) had EPTB only (Figure 1). The TB incidence decreased from 9.3 to 5.4 cases per 100,000 populations in the study period. However, the proportions of disease manifestations remained relatively stable: There was a $1.1 \%$ decrease in exclusively PTB, a $0.5 \%$ increase in both PTB and EPTB and a $0.6 \%$ increase in exclusively EPTB between 2002 and 2009.

\section{Frequency of extrapulmonary}

tuberculosis forms

When we used combined information on the main and secondary sites of disease rather than the main site only, overall EPTB affected sites increased by a factor of 1.5 (Table 1). The increases ranged from a factor of 1.2 for extrathoracic $\operatorname{LN}(3,330$ vs 4,129$)$ to a factor of 2.7 (192 vs 521) for disseminated TB.

\section{Characteristics of extrapulmonary \\ tuberculosis patients}

Overall, EPTB patients were similar to PTB patients in terms of median age and CFR (Table 2). However, they were more frequently female $(49 \%(6,956 / 14,072)$ vs 


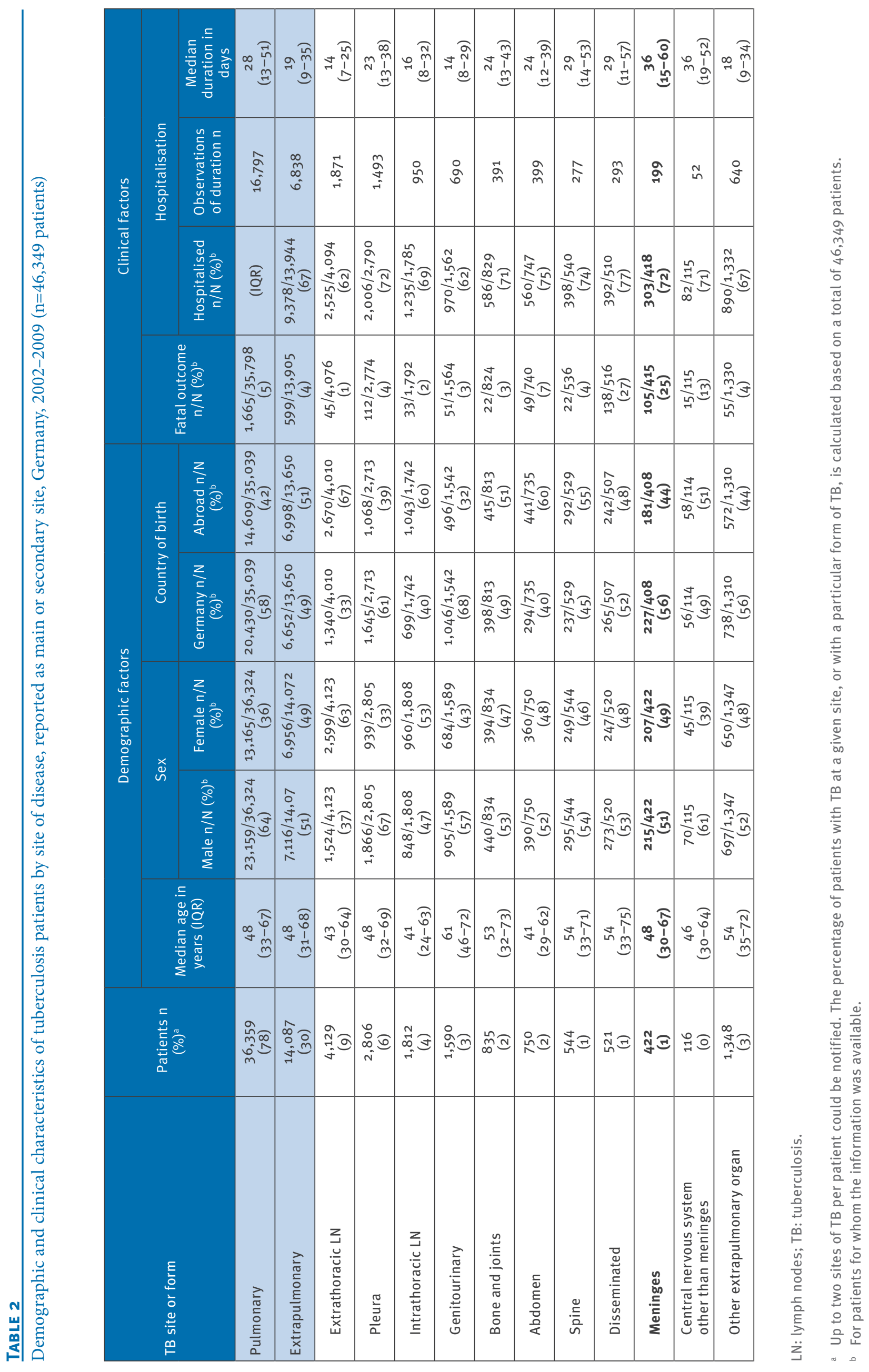




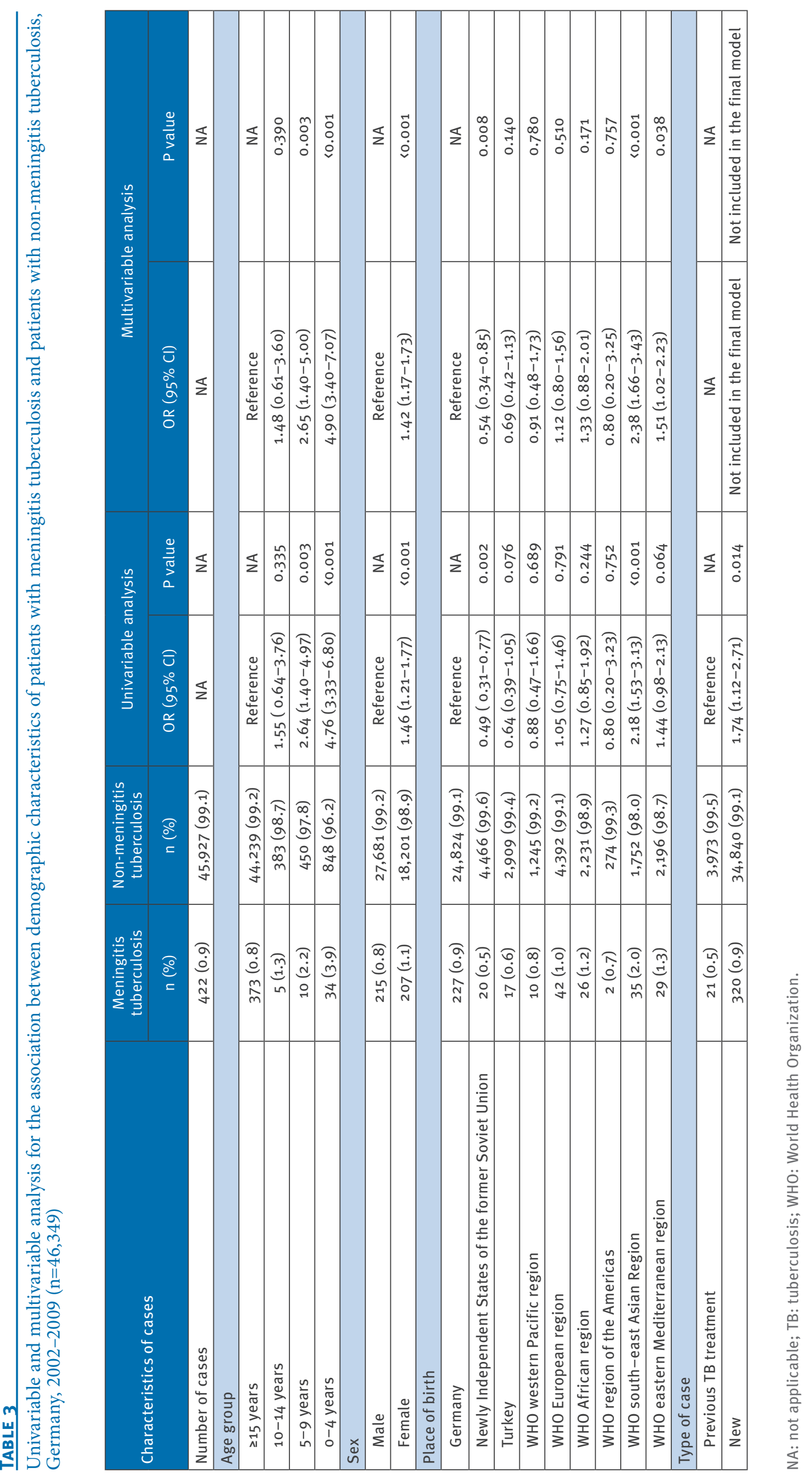


Number and incidence of meningitis tuberculosis patients by age group according to surviving outcome, Germany, 2002-2009

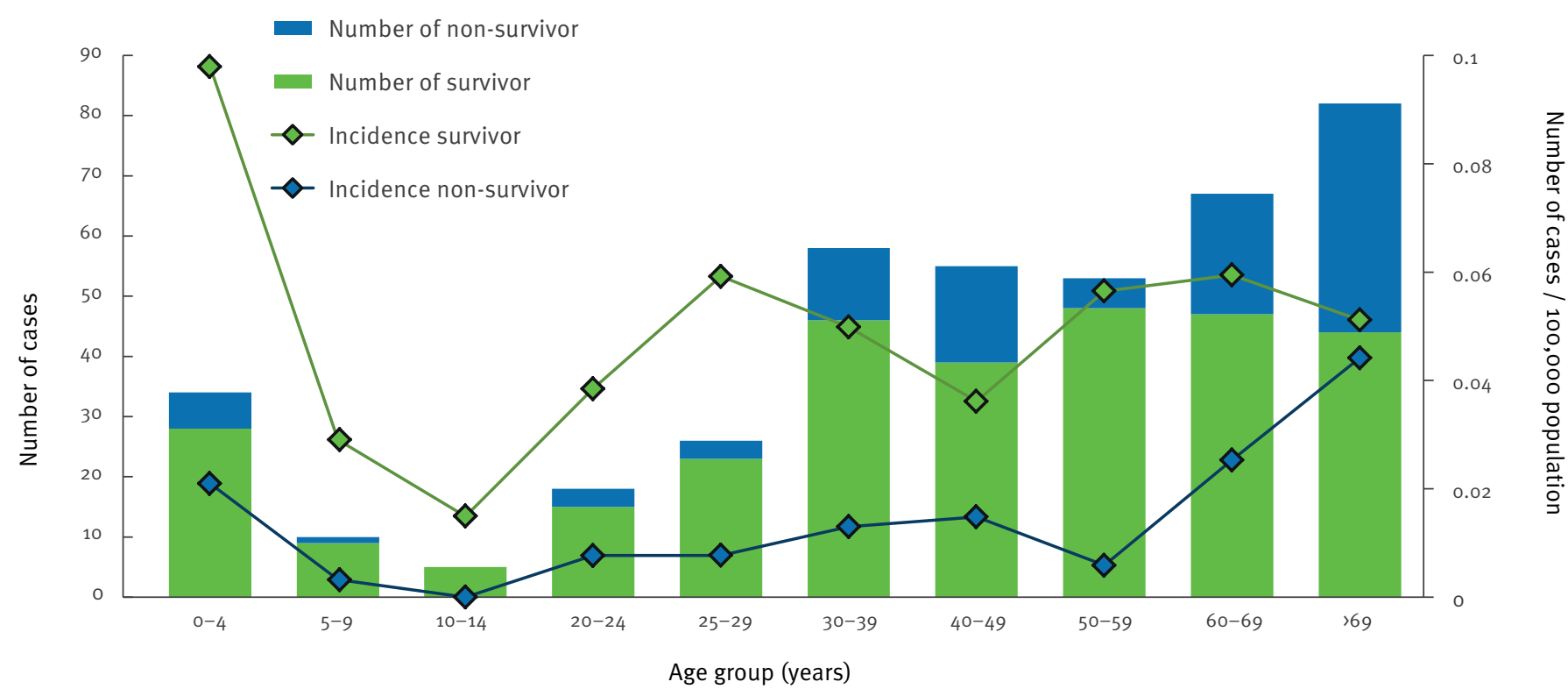

$36 \%(13,165 / 36,324))$ and more often foreign-born $(51 \%(6,998 / 13,650)$ vs $42 \%(14,609 / 35,039))$.

Across the individual extrapulmonary forms there were large differences in case characteristics. Genitourinary TB patients, for instance, were characterised by a high median age (61 years, IQR: 46-72) and only $32 \%$ $(496 / 1,542)$ of foreign-born.

The CFR was only $1 \%(45 / 4,076)$ in extrathoracic LN, but $27 \%(138 / 516)$ in disseminated TB. The median duration of hospitalisation was longest in meningitis and other CNS TB (36 days, IQR: $15-60$ and 36 days, IQR: 19-52, respectively).

\section{Meningitis tuberculosis}

Meningitis TB was reported in $0.9 \%(422 / 46,349)$ of patients as main or secondary site, and in $0.6 \%$ $(288 / 46,349)$ as the main site only. This manifestation was most frequent in children, affecting 3.9\% (34/882) of those younger than five years old, $2.2 \%(10 / 460)$ of the five to nine year-olds, and $1.3 \%(5 / 388)$ of the 10 to 14 year-olds. Though, only $0.8 \%(373 / 44,612)$ patients aged 15 years and above had meningitis, this age group accounted for $88 \%(373 / 422)$ of all meningitis patients. These proportions were stable from 2002 to 2009 in all age groups. Meningitis was more frequent among female than among male patients $(1.1 \%(207 / 18,408)$ and $0.8 \%(215 / 27,896)$, respectively).
The proportion of patients with meningitis varied by the region of origin, ranging from $0.5 \%(20 / 4,486)$ among patients born in the NIS, and $0.9 \%(227 / 25,051)$ among those born in Germany, to $2.0 \%(35 / 1,787)$ among those born in the south-east Asia WHO region (Table 3).

In multivariable analysis, compared with non-meningitis TB cases, patients with meningitis TB were more likely to be children younger than 5 years (OR: 4.90; 95\% Cl: 3.40-7.07) and children between five and nine years-old (OR: 2.65; 95\% Cl: 1.40-5.00) (Table 3). Female patients were more affected than males (OR: $1.42 ; 95 \% \mathrm{Cl}: 1.17-1.73$ ). Meningitis TB patients were less likely to be born in the NIS (OR: 0.54; 95\% $\mathrm{Cl}: 0.34-0.85$ ) than in Germany. There were no significant differences for patients born in Turkey or in the Americas, the western Pacific, the remaining European and the African WHO regions. An origin of the southeast Asia and the eastern Mediterranean region was significantly associated with meningitis (OR: 2.38; 95\% Cl: 1.66-3.43; and OR: 1.51; $95 \% \mathrm{Cl}: 1.02-2.23$, respectively).

Being a new case as well as the examined pairwise interaction terms was not statistically significant in the multivariable model, nor did they contribute to improve the model fit. They were therefore excluded from the final model. 
The CFR of meningitis TB patients was $25 \%(105 / 415)$ overall, but higher in adults than in patients younger than 15 years (27\% (98/366) vs. $14 \%$ (7/49); Figure 2). In children, meningitis accounted for about half (7/13) of all illness-related deaths.

\section{Discussion}

Our investigation of national TB surveillance data for EPTB between 2002 and 2009 indicated that in Germany analysing solely the main site of disease, as commonly done in surveillance, leads to overlooking one third of extrapulmonary manifestations reported as the secondary site. This applied to all individual EPTB manifestations including severe forms. European Centre for Disease Prevention and Control (ECDC) data indicate that, on average, about $6 \%$ of all TB patients in EU/EEA countries are reported with both PTB and EPTB [2]. This suggests that there could be similar increases in proportions of extrapulmonary forms, such as meningitis, in other countries if both main and secondary site of diseases were considered.

Patients with any extrapulmonary manifestations were more often female and born abroad. This supports earlier findings $[5,6,8,10,28,29]$ and may reflect differences in TB pathogenesis related to sex [30] and ethnicity [8], as well as risk factor patterns varying by sex and region of origin [6-8,10]. Exceptions, such as the high proportion of genitourinary TB patients being born in Germany, are partly explained by the advanced patients' age, in which the proportion of foreign-born individuals is small in Germany [31]. Such interactions across case characteristics underline the need for stratified and multivariable analyses, as we illustrated for meningitis TB.

Overall $0.9 \%$ TB patients had meningitis, whereas only $0.6 \%$ had been reported as main site of disease. Hence, re-classification increased the number of reported cases by a factor of 1.5 . A similar proportion (0.5\%) of meningitis TB was found in Germany from 1996 to 2000 , based on main site of disease only [28]. This stable proportion over time, in a context of a decrease in overall TB case numbers, suggests that there was neither a rise nor a particular progress in reducing this severe form.

Children younger than five years were most affected by meningitis; representing $8 \%$ of all meningitis cases, though accounting for less than $2 \%$ of TB patients in Germany. This is in line with a 1970 to 2000 cohort study of CNS TB patients in Canada, reporting that $10 \%$ of CNS cases were younger than five years of age [32].

While meningitis was rare (0.8\%) among TB patients who were 15 years and older, this age group accounted for $88 \%$ of all meningitis patients. A similar age distribution of meningitis cases was observed in a cohort study in Canada, whereby the age group older than 15 years contributed to $82 \%$ of all meningitis patients [32]. A similar value of $76 \%$ was found for this age group in a retrospective analysis of notified meningitis cases in Denmark [19]. These countries have age structures comparable to Germany. Meningitis TB cases in adults may be an expression of age-specific risk factors including diabetes mellitus and immune compromising conditions $[19,21]$.

In multivariable analysis, meningitis TB remained independently associated with young age and being female, similar to findings from Canada [32], as well as specific regions of origin. The association of meningitis with south-east Asia and eastern Mediterranean regions of origin is consistent with high proportions of all EPTB in patients born in these regions, and a low proportion in patients born in the NIS (data not shown). As to meningitis in particular, differences by region of origin might be shaped by the regions' HIV prevalence, which is relatively high in the south-east Asia region [33], and different levels of BCG vaccination and different BCG strains in use. BCG has been withdrawn based on risk-benefit assessments from the immunisation schedule since 1998 in Germany, in line with other low incidence countries $[34,35]$, but remains endorsed and widely used elsewhere [36]. These findings need to be interpreted with care given that meningitis case numbers were small for some regions of origin, and that risk factor patterns may differ across countries within one WHO region.

Meningitis was a severe EPTB form in terms of longest median hospital stay and case fatality. One quarter of patients with meningitis died and the CFR was almost twice as high in adults as in children. Similarly, a long term mortality study on meningitis TB patients in Denmark, from 1972 to 2008, reported that patients aged between 16 and 60 years had a 2.68 times increased risk of death compared to children [14]. The observed $14 \%$ CFR in children is higher than those described by hospital-based studies in Spain (11\%; $\mathrm{N}=28)$ and Argentina (7\%; $\mathrm{N}=40)[17,18]$. However, case inclusion criteria in those studies might have differed from surveillance data and case numbers were small.

Our investigation was solely based on national routine TB surveillance data consisting of a legally defined variable set.

The data source did not contain information on comorbidities associated with EPTB such as HIV/ acquired immunodeficiency syndrome (AIDS) or diabetes mellitus, on BCG vaccination status, on socio-behavioral factors including smoking and alcohol consumption, or treatment, precluding comprehensive risk factor analyses for EPTB forms.

Our study was subject to several limitations. First, data on hospitalisation were not complete as they do not belong to the surveillance key variables demanded and validated with high priority. A reporting bias, for instance, if longer hospitalisations were more frequently known and documented, may exist. Second, 
misclassification between meningitis and other CNS TB or differences in case ascertainment among physicians cannot be entirely ruled out. For this reason, we ran the multivariable analysis twice, first only with meningitis TB (as presented), and second merging meningitis with non-meningitis CNS TB cases as the outcome of interest. The findings of both models did not vary markedly. Only the association with the WHO African region had additionally become significant.

\section{Conclusion}

National TB surveillance data provide both, information on occurrence of disease and its severity in terms of CFR and hospital stay. This information is needed to refine estimates of the Mycobacterium tuberculosis complex-related disease burden, currently restricted to pulmonary or pooled TB data [37], and to prioritise across different pathogen-related diseases within a country [38]. Site-specific analyses of EPTB forms, as shown for meningitis, help to target future research on risk factors, clinical outcome, diagnostic tools, and preventive and therapeutic options adapted to the individual manifestations.

As to TB case management, knowledge of population groups most affected by extrapulmonary sites helps physicians to timely consider EPTB as differential diagnosis. This is important in low incidence countries with small patient numbers and risk of waning expertise. Given the frequent co-occurrence of pulmonary and extrapulmonary sites, routine screening for PTB among EPTB patients, and vice versa, is essential.

Averting meningitis and other severe TB forms through timely contact tracing and preventive chemotherapy, in agreement with national recommendations [39], needs to be of high priority.

Altogether, EPTB manifestations, including often fatal meningitis, are more widespread in Germany than so far reflected by routine analyses. We thus recommend to monitor severe disease more closely using all information on disease manifestation and severity generated by surveillance, and to transfer the gained knowledge to TB case management where awareness of EPTB is most important.

\section{Acknowledgements}

We would like to thank all notifying physicians, laboratories, local and state health departments contributing to the TB surveillance in Germany. We further thank Yvan Hutin for valuable comments on the manuscript.

\section{Conflict of interest}

The authors declare that they have no competing interests.
References

1. Rieder HL, Watson IM, Raviglione MC, Forssbohm M, Migliori GB, Schwoebel V, et al. Surveillance of tuberculosis in Europe. Working Group of the World Health Organization (WHO) and the European Region of the International Union Against Tuberculosis and Lung Disease (IUATLD) for uniform reporting on tuberculosis cases. Eur Respir J. 1996;9(5):1097-104.http:// dx.doi.org/10.1183/09031936.96.09051097 PMid:8793477

2. European Centre for Disease Prevention and Control $(E C D C) /$ World Health Organization Regional Office for Europe. Tuberculosis surveillance and monitoring in Europe 2012. Stockholm: ECDC; 2012. [Accessed o9 Nov 2012]. Available from: http://ecdc.europa.eu/en/publications/ Publications/1203-Annual-TB-Report.pdf

3. Cruz AT, Starke JR. Pediatric tuberculosis. Pediatr Rev. 2010;31(1):13-25. http://dx.doi.org/10.1542/pir.31-1-13 PMid:20048035

4. Sharma SK, Mohan A. Extrapulmonary tuberculosis. Indian J Med Res. 2004;120(4):316-53. PMid:15520485

5. Peto HM, Pratt RH, Harrington TA, LoBue PA, Armstrong LR. Epidemiology of extrapulmonary tuberculosis in the United States, 1993-2006. Clin Infect Dis. 2009;49(9):1350-7. http:// dx.doi.org/10.1086/605559 PMid:19793000

6. Fiske CT, Griffin MR, Erin H, Warkentin J, Lisa K, Arbogast PG, et al. Black race, sex, and extrapulmonary tuberculosis risk: an observational study. BMC Infect Dis. 2010;10:16. http://dx.doi. org/10.1186/1471-2334-10-16 PMid:20096113 PMCid:2823615

7. Yang Z, Kong Y, Wilson F, Foxman B, Fowler AH, Marrs CF, et al. Identification of risk factors for extrapulmonary tuberculosis. Clin Infect Dis. 2004;38(2):199-205. http://dx.doi. org/10.1086/380644 PMid:14699451

8. Kruijshaar ME, Abubakar I. Increase in extrapulmonary tuberculosis in England and Wales 1999-2006. Thorax. 2009;64(12):1090-5. http://dx.doi.org/10.1136/thx.2009.118133 PMid:19850965

9. Cowie RL, Sharpe JW. Extra-pulmonary tuberculosis: a high frequency in the absence of HIV infection. Int J Tuberc Lung Dis. 1997;1(2):159-62. PMid:9441081

10. te Beek LA, Van der Werf MJ, Richter C, Borgdorff MW. Extrapulmonary Tuberculosis, by Nationality, the Netherlands 1993-2001. Emerg Infect Dis. 2006;12(9):1375-82. http:// dx.doi.org/10.3201/eid1209.050553 PMid:17073086 PMCid:3294726

11. Musellim B, Erturan S, Sonmez Duman E, Ongen G. Comparison of extra-pulmonary and pulmonary tuberculosis cases: factors influencing the site of reactivation. Int J Tuberc Lung Dis. 2005;9(11):1220-3. PMid:16333928

12. Lin H-H, Ezzati M, Chang H-Y, Murray M. Association between tobacco smoking and active tuberculosis in Taiwan. Am J Respir Crit Care Med. 2009;18o(5):475-80. http://dx.doi.org/10.1164/ rccm.200904-05490C PMid:19542475

13. Garcia-Rodriguez JF, Alvarez-Diaz H, Lorenzo-Garcia MV, Marino-Callejo A, Fernandez-Rial A, Sesma-Sanchez P. Extrapulmonary tuberculosis: epidemiology and risk factors. Enferm Infecc Microbiol Clin. 2011;29(7):502-9. http://dx.doi. org/10.1016/j.eimc.2011.03.005 PMid:21570159

14. Christensen A-SH, Roed C, Omland LH, Andersen PH, Obel N, Andersen $\AA$ B. Long-Term mortality in patients with tuberculous meningitis: A Danish nationwide cohort study. PLoS One. 2011;6(11):e27900. http://dx.doi.org/10.1371/journal. pone.0027900 PMid:22132165 PMCid:3222654

15. Detjen AK, Magdorf K. [Characteristics of childhood tuberculosis]. Pneumologie. 2009;63(4):207-18. German. http://dx.doi.org/10.1055/s-0028-1100827 PMid:19259916

16. Porkert MT, Sotir M, Parrott-Moore P, Blumberg HM. Tuberculous meningitis at a large inner-city medical center. Am J Med Sci. 1997;313(6):325-31. http://dx.doi. org/10.1097/00000441-199706000-00002 PMid:9186145

17. Jordán Jiménez A, Tagarro García A, Baquero Artigao F, del Castillo Martín F, Borque Andrés C, Romero MP, et al. [Tuberculous meningitis: a review of 27 years]. An Pediatr (Barc). 2005;62(3):215-20. Spanish. http://dx.doi. org/10.1157/13071835

18. Paganini H, Gonzalez F, Santander C, Casimir L, Berberian G, Rosanova MT. Tuberculous meningitis in children: clinical features and outcome in 40 cases. Scand J Infect Dis. 2000;32(1):41-5. http://dx.doi. org/10.1080/00365540050164209 PMid:10716076

19. Christensen AS, Andersen AB, Thomsen VO, Andersen PH, Johansen IS. Tuberculous meningitis in Denmark: a review of 50 cases. BMC Infect Dis. 2011;11:47. http://dx.doi. org/10.1186/1471-2334-11-47 PMid:21342524 PMCid:3050726

20. Wallgren A. The time-table of tuberculosis. Tubercle. 1948;29(11):245-51. http://dx.doi.org/10.1016/ So041-3879(48)80033-4 
21. Thwaites G, Chau TT, Mai NT, Drobniewski F, McAdam K, Farrar F. Tuberculous meningitis. J Neurol Neurosurg Psychiatry. 2000;68(3):289-99. http://dx.doi.org/10.1136/jnnp.68.3.289 PMid:10675209 PMCid:1736815

22. Visser DH, Schoeman JF, Van Furth AM. Seasonal variations in the incidence rate of tuberculous meningitis is associated with sunshine hours. Epidemiol Infect. 2012;1-4. [Epub ahead of print].

23. Berenguer J, Moreno S, Laguna F, Vicente T, Adrados $M$, Ortega A, et al. Tuberculous meningitis in patients infected with the human immunodeficiency virus. N Engl J Med. 1992;326(10):668-72. http://dx.doi.org/10.1056/ NEJM199203053261004 PMid:1346547

24. Colditz GA, Berkey CS, Mosteller F, Brewer TF, Wilson ME, Burdick $E$, et al. The efficacy of bacillus Calmette-Guerin vaccination of newborns and infants in the prevention of tuberculosis: meta-analyses of the published literature. Pediatrics. 1995;96(1 Pt 1):29-35. PMid:7596718

25. Robert Koch-Institut (RKI). Bericht zu Epidemiologie der Tuberkulose in Deutschland für 2010. [Report on the epidemiology of tuberculosis in Germany for 2010]. Berlin: RKI. [Accessed o9 Nov 2012]. German. Available from: www.rki.de/ DE/Content/InfAZ/T/Tuberkulose/Download/TB2010.pdf

26. Statistisches Bundesamt Deutschland. Bevölkerung. [Accessed o9 Nov 2012]. German. Available from: http://www.destatis.de

27. Robert Koch-Institut (RKI). Falldefinitionen des Robert KochInstituts zur Übermittlung von Erkrankungs- oder Todesfällen und Nachweisen von Krankheitserregern. [Case definitions for the surveillance of notifiable infectious diseases in Germany]. Berlin: RKI; 2007. [Accessed og Nov 2012]. German. Available from: http://edoc.rki.de/documents/rki_ab/resqbo8cCmdrg/ PDF/22yDAlgk34pw.pdf

28. Forssbohm M, Zwahlen M, Loddenkemper R, Rieder HL. Demographic characteristics of patients with extrapulmonary tuberculosis in Germany. Eur Respir J. 2008;31(1):99-105. http://dx.doi.org/10.1183/09031936.00020607 PMid:17804450

29. 29. Rieder HL, Snider DE Jr., Cauthen GM. Extrapulmonary tuberculosis in the United States. Am Rev Respir Dis. 1990;141(2):347-51. PMid:2301852

30. Neyrolles O, Quintana-Murci L. Sexual inequality in tuberculosis. PLoS Med. 2009;6(12):e1000199. http:// dx.doi.org/10.1371/journal.pmed.1000199 PMid:20027210 PMCid:2788129

31. Hauer B, Brodhun B, Altmann D, Fiebig L, Loddenkemper $\mathrm{R}$, Haas W. Tuberculosis in the elderly in Germany. Eur Respir J. 2011;38(2):467-70. http://dx.doi. org/10.1183/09031936.00199910 PMid:21804163

32. Phypers M, Harris T, Power C. CNS tuberculosis: a longitudinal analysis of epidemiological and clinical features. Int J Tuberc Lung Dis. 2006;10(1):99-103. PMid:16466045

33. Joint United Nations Programme on HIV/AIDS (UNAIDS). UNAIDS report on the global AIDS epidemic 2010. Geneva:UNAIDS. [Accessed o9 Nov 2012]. Available from: http://www.unaids. org/globalreport/

34. Robert Koch-Institut. Impfempfehlungen der Ständigen Impfkomission (STIKO) am Robert Koch Institut/Stand: März 1998. [Recommendations of the Standing Committee on Vaccination Recommendations (STIKO) at the Robert Koch Institute: March 1998]. Epidemiologisches Bulletin. 1998;15/98. German.

35. Infuso A, Falzon D. European survey of BCG vaccination policies and surveillance in children, 2005. Euro Surveill. 2006;11(3): :pii=604. Available from: http://www.eurosurveillance.org/ ViewArticle.aspx?Articleld $=604$

36. The BCG world atlas. A database of global BCG vaccination policies and practice. [Accessed o9 Nov 2012]. Available from: www.bcgatlas.org/

37. European Centre for Disease Prevention and Control (ECDC). Current and future burden of communicable diseases in the European Union and EEA/EFTA countries (BCoDE). Stockholm: ECDC; 2010. [Accessed o9 Nov 2012]. Available from: http:// www.ecdc.europa.eu/en/publications/Publications/Forms/ ECDC_DispForm.aspx?ID=688

38. Balabanova Y, Gilsdorf A, Buda S, Burger R, Eckmanns T, Gärtner B, et al. Communicable diseases prioritized for surveillance and epidemiological research: results of a standardized prioritization procedure in Germany, 2011. PLoS One. 2011;6(10):e25691. http://dx.doi.org/10.1371/journal. pone.0025691 PMid:21991334 PMCid:3186774 